\title{
Commentary: What is the value of a case report for creating medical evidence at times of prospective randomized trials?
}

\author{
Torsten Doenst, $\mathrm{MD}, \mathrm{PhD},{ }^{\mathrm{a}}$ and Axel Haverich, $\mathrm{MD}, \mathrm{PhD}^{\mathrm{b}}$
}

\footnotetext{
From the ${ }^{\mathrm{a}}$ Department of Cardiothoracic Surgery, Jena University Hospital, Friedrich-Schiller-University of Jena, Jena, Germany; and ${ }^{\mathrm{b}}$ Department of Cardiothoracic, Transplantation and Vascular Surgery, Hannover Medical School, Hannover, Germany.

Disclosures: Authors have nothing to disclose with regard to commercial support.

Received for publication June 27, 2019; accepted for publication June 28, 2019; available ahead of print Aug 20, 2019.

Address for reprints: Torsten Doenst, $\mathrm{MD}, \mathrm{PhD}$, Department of Cardiothoracic Surgery, Friedrich-SchillerUniversity of Jena, Am Klinikum 1 07747, Jena, Germany (E-mail: doenst@med.uni-jena.de).

J Thorac Cardiovasc Surg 2020;159:e51-2

$0022-5223 / \$ 36.00$

Copyright (C) 2019 by The American Association for Thoracic Surgery

https://doi.org/10.1016/j.jtcvs.2019.06.075
}

Cardiac surgery is a young field that has developed dramatically in the second half of the last century. ${ }^{1}$ This development has set the gold standard for many cardiac disease conditions, starting with the correction of cardiac malformations in the pediatric age to treating acquired valve and coronary diseases. Practically all of these achievements were made without testing their effects through prospective randomized trials. ${ }^{2}$ Today, such trials are more and more often required for new methodologies to be approved by the authorities (www.fda.gov/medical-devices). Under these circumstances, one may ask what is the value of a case report?

Osman and colleagues ${ }^{3}$ report a mitral valve replacement through the left atrial appendage in a patient with previous right-sided pneumonectomy through a sternotomy. Because of the right-sided displacement of the heart and cranial displacement of the liver, the surgical approach to the valve became a challenge. The authors evaluated the different options for their approach and opted for a redosternotomy and accessing the valve through the left atrial appendage. They were successful with an uneventful replacement of the mitral valve. So, what is the value of this case?

First of all, Osman and colleagues ${ }^{3}$ helped one patient to derive a benefit from the procedure. Because it is unlikely that many such cases will be operated in the future, one may question the need for publication of this case. However, the case illustrates that an individualized approach to a complex problem can be associated with great success. It is part of our daily work to generate such success one patient at a time, and if complexity increases so does risk. It is therefore commendable that the authors performed the described procedure, because the additional risks associated with potentially limited exposure, thin-walled left atrial appendage tissue (making bleeding complications likely), or limited pneumonectomy.

\section{References}

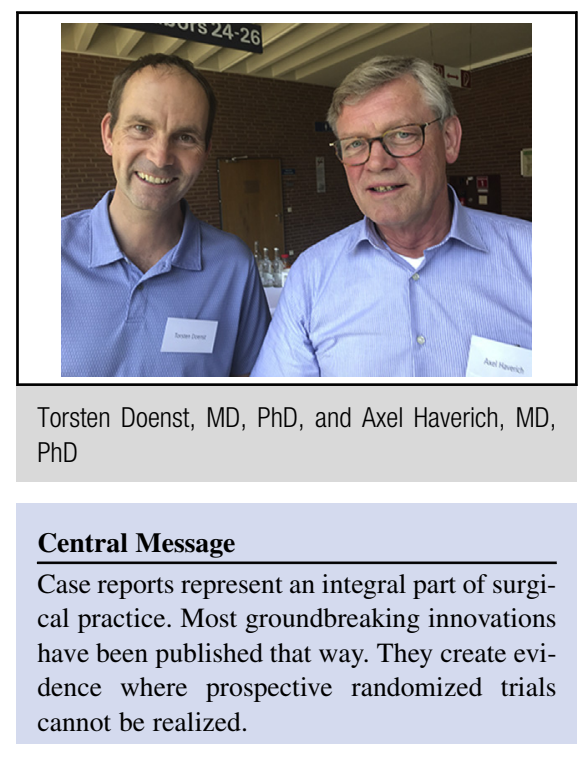

See Article page e47.

access to the aorta may make surgeons shy away from undertaking this endeavor, especially in times of individual outcomes reporting. ${ }^{4}$

Most important, however, there are many situations (possibly not as obvious as this one) where it is unlikely or impossible to test the effects of surgery in prospective randomized trials. ${ }^{5}$ Probably still surprising to most of us, the majority of groundbreaking innovations in surgery over the past 80 years were reported through case reports or small case series ${ }^{2}$ and not a single one through prospective randomized trials. By definition, the majority of congenital heart defects for instance are categorized as "rare disease," where retrospective outcome measures remain the gold standard in creating evidence for a surgical procedure. We therefore believe that case reports will remain an important tool for surgeons to enrich our armamentarium for daily surgical practice and to create evidence. Every so often, innovative thinking and new discoveries usually start with one challenging case, such as this one with mitral regurgitation and previous

1. Doenst T, Schlensak C, Schibilsky D, Faerber G. Do we need basic research in cardiac surgery? J Thorac Cardiovasc Surg. 2018;66:2-6. 
2. Weber S, Haverich A. Bahnbrechende chirurgische innovationen in Deutschland Der Chirurg. 2016;87:433-7.

3. Osman M, Parizkova B, Barker A, Nashef SAM. Mitral valve replacement through left atrial appendage 28 years after right pneumonectomy. J Thorac Cardiovasc Surg. 2020;159:e47-9.
4. Jha AK. Public reporting of surgical outcomes: surgeons, hospitals, or both? JAMA. 2017;318:1429-30.

5. Doenst T, Lamelas J. Do we have enough evidence for minimally-invasive cardiac surgery? A critical review of scientific and non-scientific information. J Thorac Cardiovasc Surg. 2017;58:613-23. 